\title{
Wire EDM mechanism of MMCs with the variation of reinforced particle
} size

\author{
A. Pramanik ${ }^{1 *}$, G. Littlefair ${ }^{2}$ \\ ${ }^{1}$ Department of Mech. Engineering, Curtin University, Bentley, WA, Australia \\ ${ }^{2}$ School of Engineering, Deakin University, Waurn Ponds, VIC, Australia
}

*Corresponding author,

Email: alokesh.pramanik@ curtin.edu.au,akprama@yahoo.com,

Fax: +61 (0)892662681, Phone: +61 (0)8 92667981.

\begin{abstract}
The size of reinforced particles notably affects the EDM of MMCs. This paper explores the mechanism of wire EDM of MMCs with different sizes of reinforced particles as well as corresponding unreinforced matrix material. The mechanisms of material removal, surface generation and taper kerf formation were investigated. This study shows that the particles' ability to protect matrix materials from intense heat of electric arc controls the material removal rate, surface generation and taper of kerf. The low melting point matrix material is removed very easily but the heat resistance reinforced particles delays the removal of material and facilitates transfer of the workpiece material to wire electrode and vice versa. Thus, the material stays longer in touch with intense heat and the affects the surface generation, wire electrode wear and width of the kerf.
\end{abstract}

Keyword: edm, machinability, matrix, composites, wire, particles, aluminium, surface, reinforcement

\section{Introduction}

Machining processes remove unwanted material from a bulk workpiece to introduce the shape of the final product. The unwanted material is separated as chips by plastic deformation due to application of force by sharp cutting tools in traditional machining [1, 2]. The complex deformation mechanism due to presence of reinforcement [3] in metal matrix composites (MMCs) causes high tool wear during traditional machining. With the advent of new technologies sharp cutting tools are not used in non-traditional machining. In this case, excess material is removed by mechanical, thermal, electrical or chemical energy or combinations of these energies. Electro-discharge machining (EDM) belongs to the category of non-conventional machining where material is removed due to the successive 
electrical discharges between tool which is known as electrode and the workpiece which is machined where a dielectric fluid is present [4]. Electrically conductive materials with any hardness can be machined using this method [5]. Thus, particle reinforced metal matrix material which is difficult to machine by traditional processes, has the potential to be machined by EDM [6]. Though, complications connected to precision and efficient processing of MMCs are significant in manufacturing [7-9].

There are many research on EDM of particle reinforced MMCs. Though the presence of the reinforcements slow the material removal rate EDM are applied to machine MMCs. The efficiency of EDM process is controlled by discharge current, pulse duration and properties of MMC's [10, 11]. The ceramic reinforcement's don't melt due to the EDM which suggest that material removals in MMC's occur through vaporising and melting of matrix material [10]. Microscopic craters are generated on the surface machined by EDM due to random spark discharge. The extent of the craters is controlled by the discharge energy [12]. The re-cast layer thickness rises when discharge current increases and pulse on-times become longer [10]. Gatto and Iuliano [13] investigated influence of particle and whisker on the machined surface after EDM. It was noted that the speeds of machining for both MMCs were similar. The roughness of newly generated surface of $15 \%$ whiskers reinforced MMC is less than that of $20 \%$ particles reinforced MMC. Rozenek et al. explored the influence of pulse on-time, pulse off-time, discharge current and voltage on the speed as well as surface finish for WEDM of $\mathrm{Al}_{2} \mathrm{O}_{3}$ and $\mathrm{SiC}$ particles reinforced aluminium alloy MMCs [14]. The roughness of the machined surface and machining speed were found to rise with the rise of voltage, discharge energy and pulse-on time. It was also recorded that the type of reinforcement affects the machining speed. The highest machining speeds of $\mathrm{SiC}$ and $\mathrm{Al}_{2} \mathrm{O}_{3}$ reinforced MMCs are around 3 and 6.5 times smaller than that of the corresponding matrix material. Guo et al. investigated WEDM of $20 \% \mathrm{Al}_{2} \mathrm{O}_{3}$ particle reinforcement Al6061 composite [15]. The experiments show rough surface finish for high as well as low energy EDM. A little influence of the electrical parameters on surface roughness was noted in this investigation though those influenced machining speed significantly [16]. Wire breakage generally happens when low energy is employed by low pulse duration and machining voltage due to blind feeding. Machining efficiency improves by higher pulse duration, voltage and discharge current at appropriate pulse interim. Yan et al. [17] found that the speed of machining nonreinforced alloy was highest of all the workpieces though similar machining speed was noted for $10 \%$ and $20 \%$ particle reinforced composites. The increase of the reinforcement volume fraction causes breakage of wire, narrower slit, rougher machined surface finish, and wider and deeper craters on the wire surface. For the 20 vol.\% reinforced MMCs, the wire shifted due to impedance by 
protruding of reinforcement particles in the slit which causes bandings on the newly generated surface when the tension in the wire is low. Yan et al. [17] suggested lower tension in wire, higher rate of flushing and higher speed of wire may avoid breakage of wire during WEDM of MMCs. Patil and Brahmankar [18] noted that the finish of machined surfaces of MMCs was higher than that of the matrix material. Breakage of wire electrode limits the machining speed of MMCs. Manna and Bhattacharyya [19] performed EDM of silicon carbide aluminium composite and explored the contributions of WEDM variables on different machining outcomes. They noted that the open-gap voltage is the leading factor for controlling the rate of material removal and machining speed. Tension and feed rate of wire electrode mostly affects surface roughness. Saha et al. [20] investigated the influence of different input variables on the machining speed and kerf width during WEDM of 5 vol.\% TiC reinforced $\mathrm{Fe}$ in situ MMC. The EDM process generates TiC particles and $\mathrm{Fe}_{2} \mathrm{O}_{3}$ which cause the unstable machining. They noted that the increase of gap voltage decreases the machining speed and increases the width of kerf. The increase of pulse on-time raises the machining speed and the width of kerf. Similarly, Liu et al. [21] explored the influence of different input variables on material removal rate during WEDM of $\mathrm{Al}_{2} \mathrm{O}_{3}$ particle reinforced 6061 aluminium alloy MMC. They found that the rise current or electrolyte concentration raises the rate material removal by promoting the electrochemical processes. Pramanik et al. [22] investigated effect of the size of reinforced particles on WEDM of MMCs in terms of material removal rate, surface integrity, and wear of wire electrodes. They noted that larger particles significantly reduced the MRR. The machined surfaces were full of solidified melted matrix, splashes of melted material, cavities, and blisters, which are not significantly affected by particle size. Spattering and splashing might have contributed to the transfer of materials between the electrode wire and MMCs. The diameter of the wire electrode reduced with the increased particle size after machining. Sidhu et al., [23] noted that the workpiece, electrode material properties, and pulse off time significantly contribute in the residual stresses generation. Percentage of reinforced particulates and matrix conductivity affect the development of residual stresses significantly. The deposition of fragmented particles of composite electrode $(\mathrm{Cu}-\mathrm{Gr})$ results in high residual stresses.

The above discussion points out that the progresses on EDM of particle reinforced MMCs are very good and many interesting outcomes have been obtained in this field so far. However, the mechanisms of material removal, surface generation and taper kerf formation have never been investigated with the variation of reinforcement particle size though the size of the reinforcement significantly affects the properties of the MMCs. It is well established that the smaller size of the reinforcement incorporates better mechanical properties in MMCs compare to that of bigger size of 
the reinforcement $[24,25]$. There is a trend for MMCs to have smaller size of reinforced particles to widen its application. This suggests the importance to investigate the mechanism of EDM on MMCs with different size of reinforced particles. To address this issue, this study investigated three types of MMCs with different reinforcement size $(13,3$ and $0.7 \mu \mathrm{m})$ and the corresponding matrix material under constant EDM parameters. The mechanisms of material removal rate, surface generation and kerf/slit have been investigated in details. This will provide in-depth understanding on the responses of the MMCs with different particle sizes on the EDM process for the researchers and industry people.

\section{Materials and methods}

A series of WEDM of particle reinforced MMCs (with varying particle size) were carried out by FANUC ROBOCUT $\alpha-0 \mathrm{iD}$ machine. The metal matrix composites were made of 6061 aluminium alloy reinforced with $10 \mathrm{vol} \% \mathrm{SiC}$ particles of 13, 3, $0.7 \mu \mathrm{m}$ size (approximately) were machined. In addition, unreinforced 6061 aluminum matrix material was also machined under similar condition to understand the effect of reinforcement as well as size of reinforcement. All the materials were hot extruded and treated $\mathrm{T} 1$ condition. The fixed parameters during machining were: wire speed 10 $\mathrm{m} / \mathrm{min}$, wire tension $1200 \mathrm{gf}$, flushing rate $10 \mathrm{l} / \mathrm{min}$, open circuit voltage $85 \mathrm{~V}$, servo voltage $44 \mathrm{~V}$, pulse on time $4 \mu \mathrm{s}$, hole diameter $12 \mathrm{~mm}$ and brass wire of diameter $0.25 \mathrm{~mm}$ coated with zinc. The machining conditions were selected based on the data presented in the literature and the existing facilities in the laboratory. A slot of $7 \mathrm{~mm}$ long was produced on a plate of $137 \times 42 \times 9 \mathrm{~mm}^{3}$ in each experiment. Several slots were produced in each workpiece under similar machining condition. The cutting speed, kerf with, surface roughness and wire wear were investigated in this study.

\section{Results and discussion}

Fig. 1 shows that lowest material removal rate occurs when the particles were biggest considered in this investigation. It is very natural that the bigger particles have the ability to protect the matrix material from melting and slow down the material removal rate. However, the material removal rate did not increase in the proportion of the decrease of the particle size. 


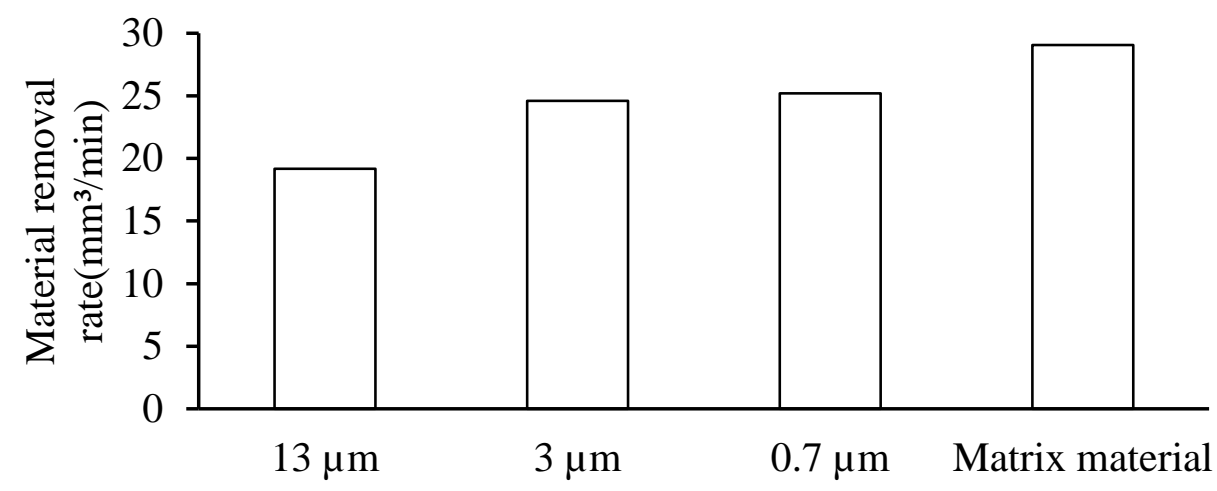

Fig. 1 Influence of particle size on material removal rate

The Fig. 2 presents the effect of particle size on the arithmetic mean surface roughness $\left(\mathrm{R}_{\mathrm{a}}\right)$, total roughness profile height $\left(\mathrm{R}_{\mathrm{t}}\right)$ and maximum roughness profile height $\left(\mathrm{R}_{\mathrm{z}}\right)$. It shows that the variation of these surface parameters is minor among the materials considered in this investigation though the biggest reinforcement size gives the smaller surface parameters. Then those increased with the reduction of the particle size to $3 \mu \mathrm{m}$. However, with the further decrease of particle size or the absence of the reinforcement did not affect the surface finish at all. It seems that the lower speed at higher particle size produces better surface finish but the particles don't affect the surface parameters when the particle size reduced to certain size. The pictures of the machined surfaces of all the materials are given in Fig. 3. All the surfaces are very similar qualitatively. All surfaces consist of solidified melted materials, crater due to spark and blisters due to splash of the molten metals. There might be reinforced particles on the newly generated surfaces of MMCs but it is hard to identify as all are coated by matrix material.

The Fig. 4 presents that the kerf width rises with the decrease of particle size where the unreinforced matrix material experiences highest kerf width. In addition, the kerf width at the top surface is bigger than that in the bottom surface for all the materials but the difference between the widths of the top and bottom kerfs decreases with the reduction of the particle size. The difference is smallest for the unreinforced matrix material. The top and bottom surfaces of the kerf have some dissimilar appearances. Fig. 5 shows that the EDM related damage in the top surface of the kerf is higher than that of the bottom surface 5(a). However, with the increase of particle size the deference in damage decreases by increased damage in the bottom surfaces. For the matrix material the damage in the bottom surface is minimum but the damage of the top surface is maximum among the corresponding surface for all the materials. The profiles of kerf from EDM of different materials in the Fig. 6 show that the none of these are perfectly sraight though the wire electrode moved in a straight line. There 
are wave forms in the kerf for all the materials but the amount and size of the waves reduces with the rise of reinforcement size.

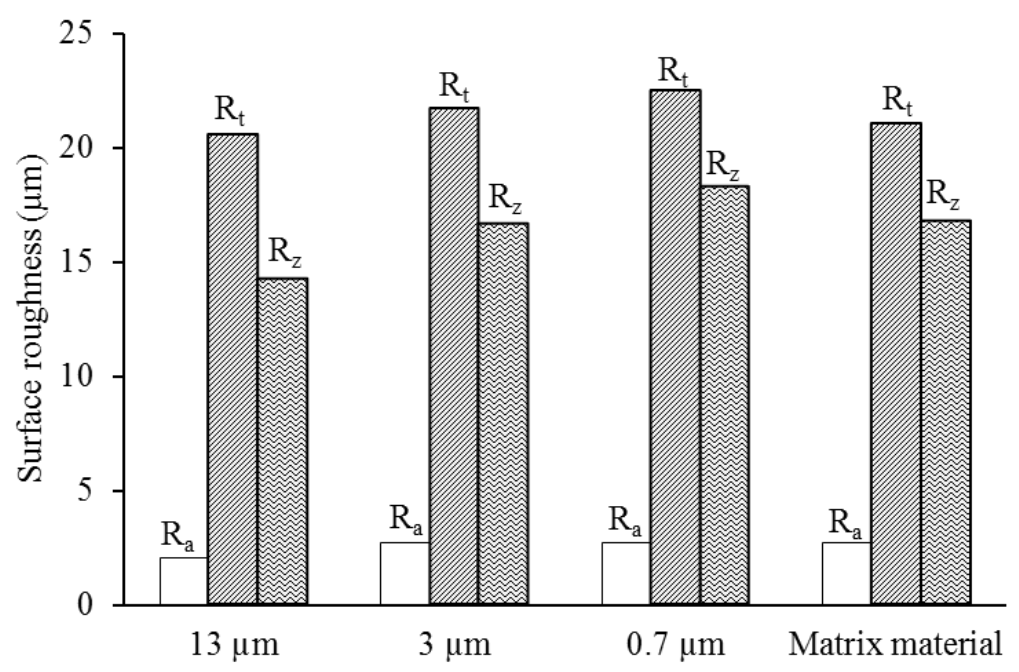

Fig. 2 Influence of the size of particles on the roughness parameters
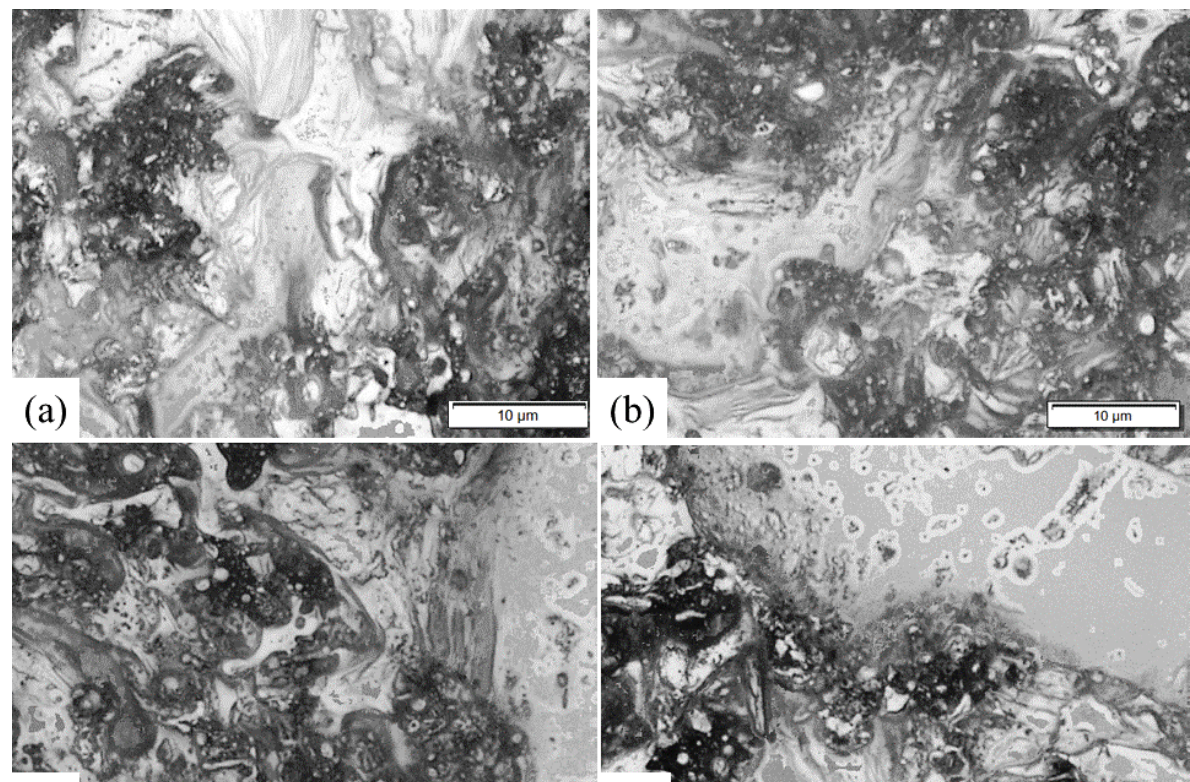

(c)

(b)

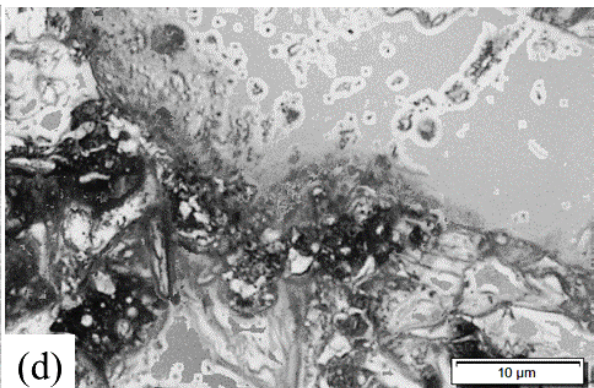

Fig. 3 Influence of the size of particles on machined surfaces MMC reinforced with particle size (a) $13 \mu \mathrm{m}$, (b) $3 \mu \mathrm{m}$, (c) $0.7 \mu \mathrm{m}$ and (d) unreinforced matrix material 


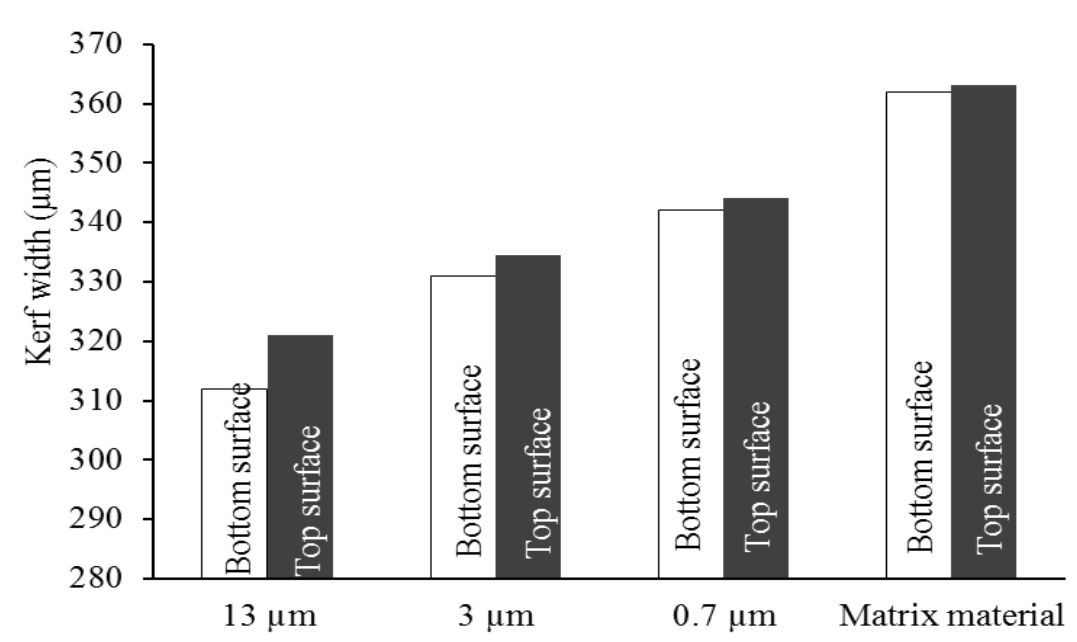

Fig. 4 Influence of the size of particle on the kerf width

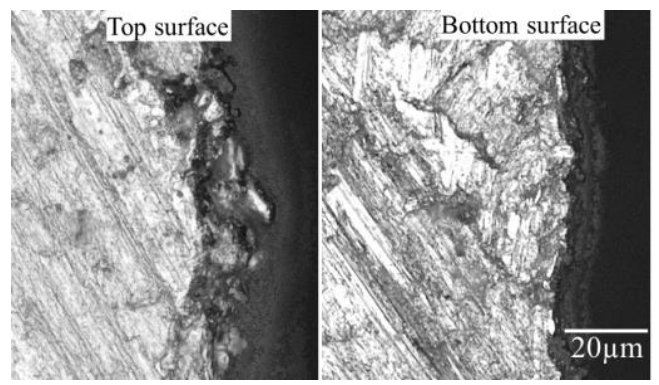

(a) Matrix material

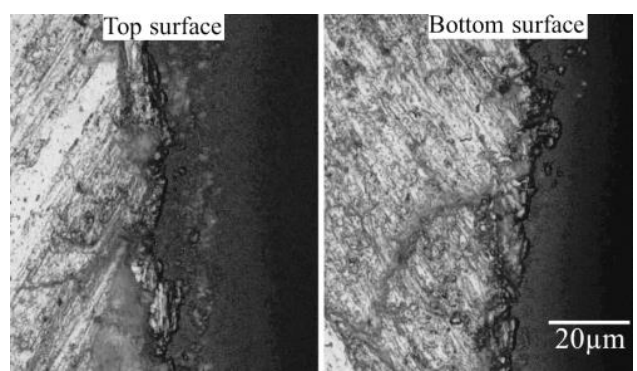

(c) MMC with particle size $3 \mu \mathrm{m}$

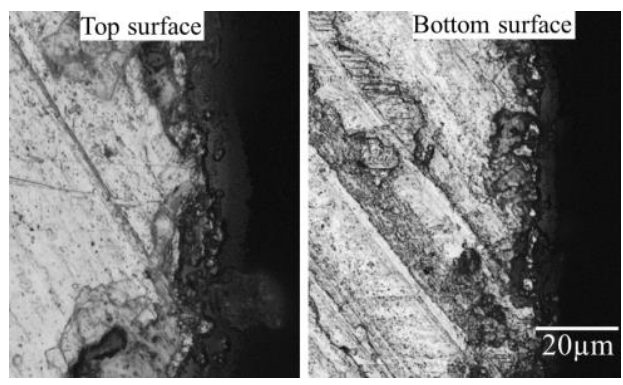

(b) MMC with particle size $0.7 \mu \mathrm{m}$

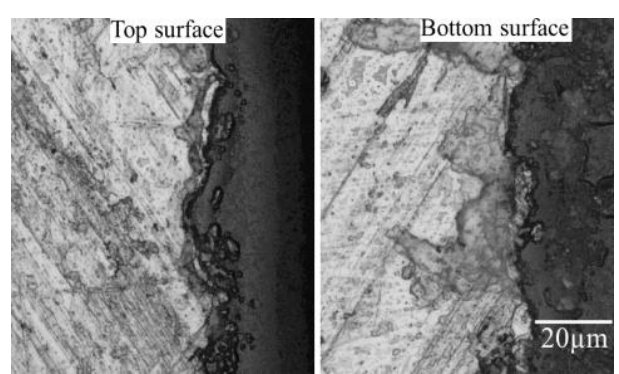

(d) MMC with particle size $13 \mu \mathrm{m}$

Fig.5 Influence of the size of particles on kerf surfaces

The Fig. 7 presents that the diameter of the wire reduces from the original size after EDM of all the materials considered in this study. However, the amount of decrease of the diameter depends on the materials. The diameter of the wire decreases with the increase of the reinforced particle size. Figs. 8 and 9 show the difference of the surface appearance of the wire electrode before and after EDM respectiveley. The wire electrode after the machining have additional material and/or melted wire material on it. It seems that the wire electrode is partially coated with the workpiece material for all the cases considered in this study. However, the presence and size of reinforced particles have not made any notable effects on the surface of the wire electrode according to Fig. 9 where all the surfaces are very similar to each other regardless of workpiece materials. 


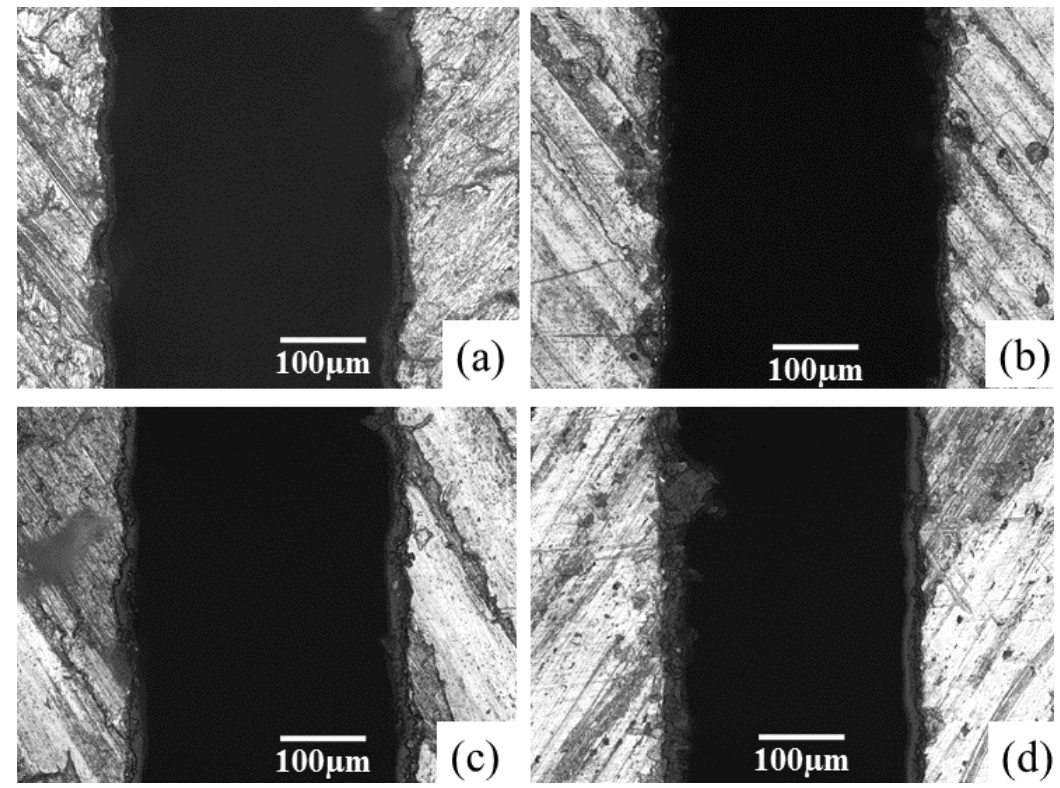

Fig. 6 Influence of the size of particles on kerf profiles (a) unreinforced matrix material, and MMC reinforced with particle size (b) $0.7 \mu \mathrm{m}$, (c) $3 \mu \mathrm{m}$ and (d) $13 \mu \mathrm{m}$.

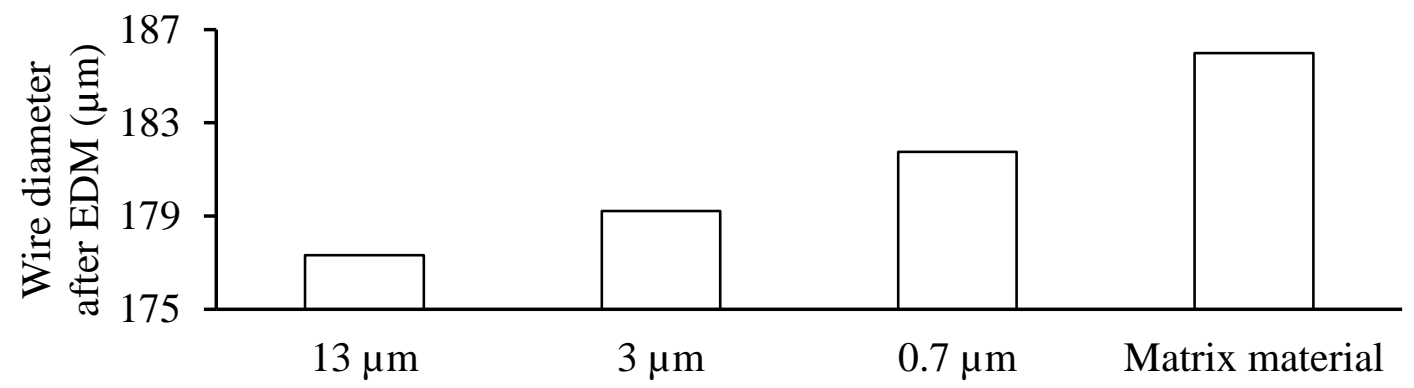

Fig. 7 Influence of the size of particles on the wire electrode diameter after EDM

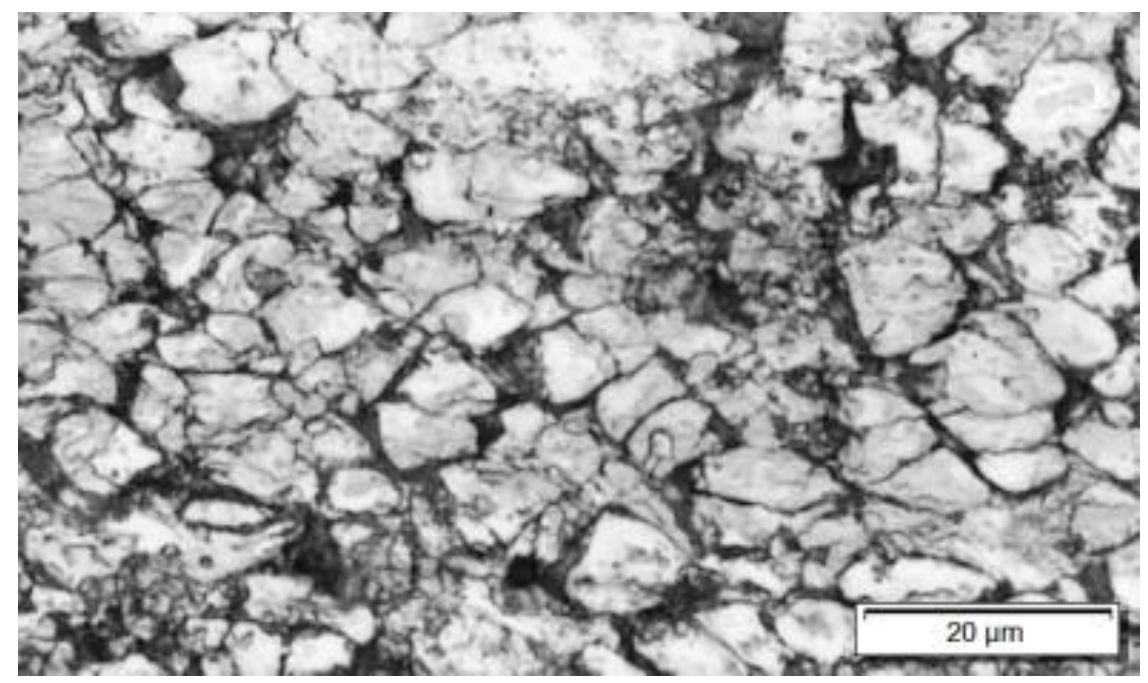

Fig. 8 The surface of wire electrode before EDM 

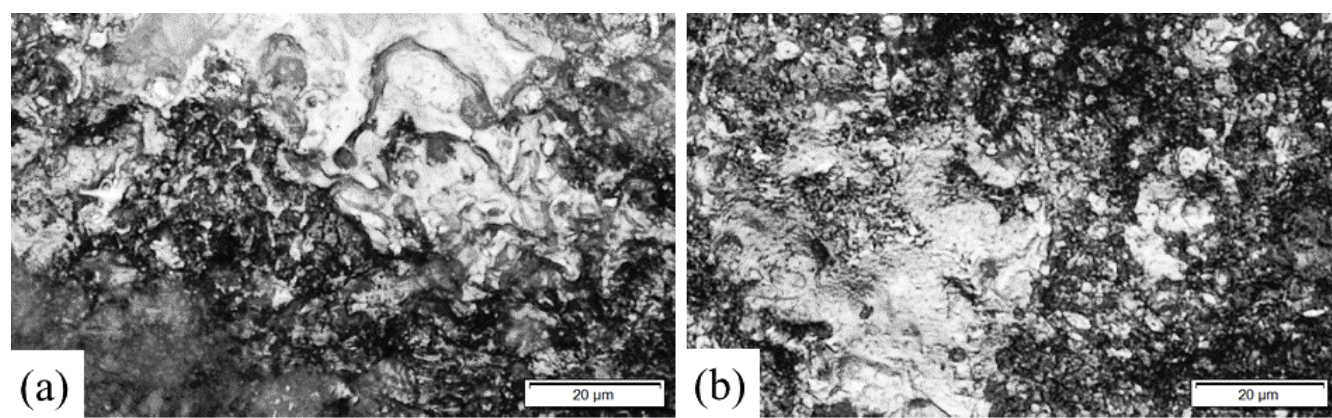

(b)
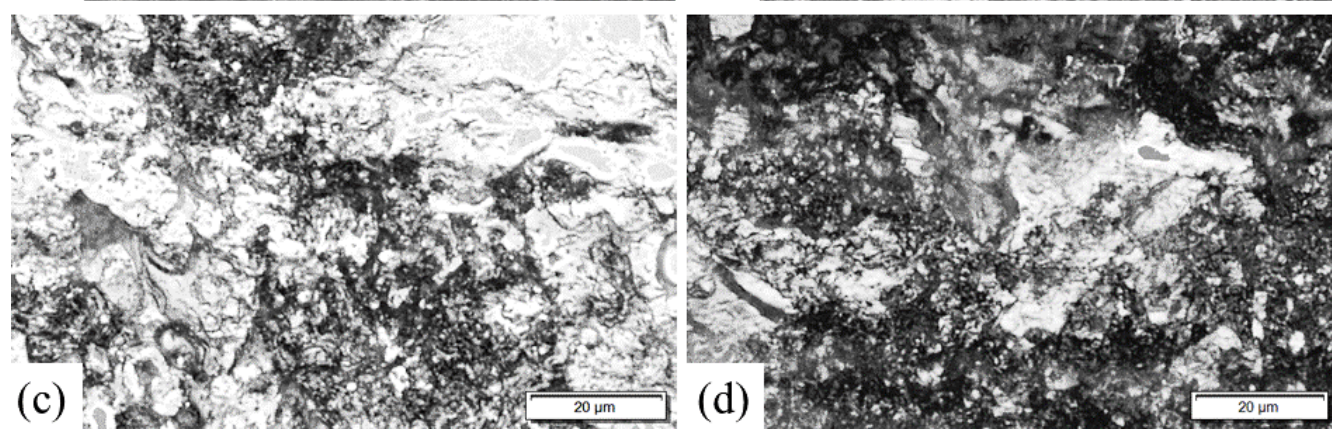

Fig. 9 Influence of the size of particles on the surface of wire electrode after EDM (a) unreinforced matrix material, and MMC reinforced with particle size (b) $0.7 \mu \mathrm{m}$, (c) $3 \mu \mathrm{m}$ and (d) $13 \mu \mathrm{m}$.

The nonconductive and high melting point reinforcements decrease the thermal and electrical conductivity of MMCs which reduces the speed and introduces additional complexity during EDM of MMCs [26, 27]. The rate of material removal is generally higher at the start of machining but it reduces then because of the entrapment of reinforced particles into the spark gap [28]. The particles protect the matrix material from melting and reduce the speed but the capability of protection reduces significantly when the particle size reduces further in the similar proportion [22,27]. Thus, there is a chance that the material removal rate will be equivalent to that of matrix material when the size of the particles very small. In this study, the maximum rate of material removal was achieved when the particles were absent in the matrix material. It seems that when the particle size is small enough compare to the diameter of the wire electrode the MMCs and matrix materials undergoes similar kind of machining mechanism.

According to Pramanik et al., [26] the wire encounters the ceramic particles and the EDM process becomes different to that of monolithic metals and there are three types of situations, such as (i) the particle completely inside the slit width (PCSW), (ii) the particle partly in solid material and partly inside the projection of wire diameter (PPWD) (iii) the particle partly in solid material and partly in melted material (PPMM). The wire EDM process of particle reinforced MMC is shown in Fig. 10(a). It is seen from the literature that the wire diameter is much bigger than that of reinforced particle diameter. Thus the diameter of the wire is much bigger compare to that of particles in the figure. This 
is a graphical presentation and it is not to the scale. Figure 11(b) shows the different situations which arise due to relative location of particles with respect to the wire [26].

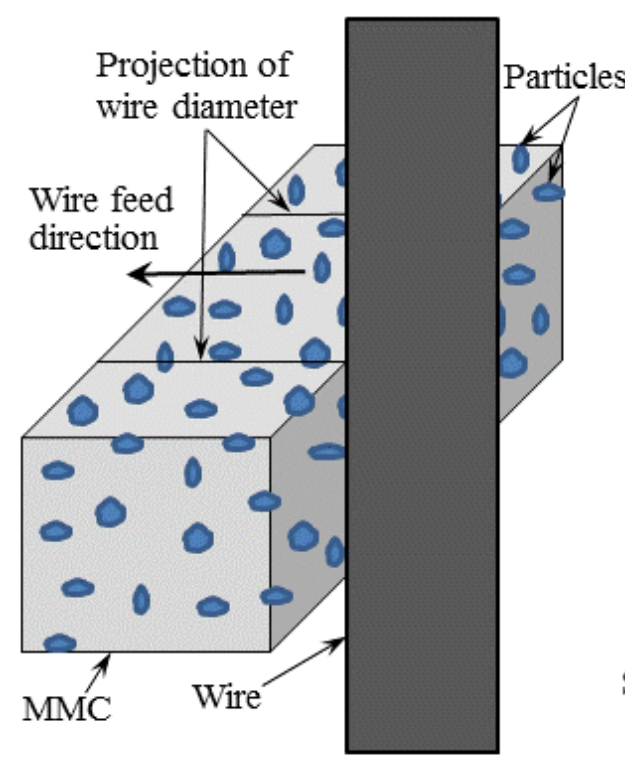

(a)

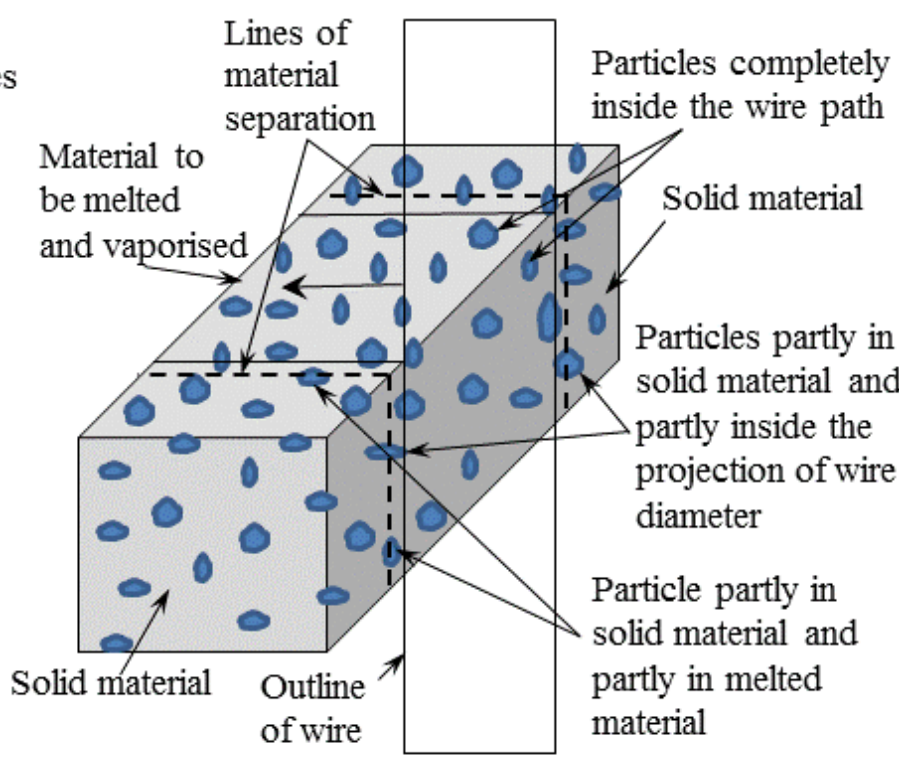

(b)

Fig. 10 Typical wire EDM process of particle reinforced MMC [26]

In this study the diameter of the wire electrode is $250 \mu \mathrm{m}$ before machining and the diameters of the reinforced particles are 13,5 , and $0.7 \mu \mathrm{m}$. Thus the ratio of the wire diameter to reinforced particle diameter becomes 19.2, 50 and 357 for the different size of the particles. It is noted from the experimental data that the clearance between the wire electrode and the kerf boundary rises with the reduction of the particle size. The maximum clearance was noted in the unreinforced matrix material and the minimum clearance was noted in the MMCs reinforced with $13 \mu \mathrm{m}$ diameter particles. The minimum clearance is $67 \mu \mathrm{m}$ which is much bigger than the particle diameter. For the other cases considered in this study, the size of the particles is much smaller compare to the clearance between the wire electrode surface and kerf boundary. Thus, scenarios "the particle partly in solid material and partly in melted material (PPMM)" and "the particle completely inside the slit width (PCSW)" mainly control the EDM process in this investigation.

Fig. 11 shows different amount of clearance between the electrode and kerf surface for different materials. The approximate clearance were 67, 76, 80 and $88 \mu \mathrm{m}$ for MMCs with reinforcement size of $13 \mu \mathrm{m}, 3 \mu \mathrm{m}, 0.7 \mu \mathrm{m}$ and the matrix material respectively. It was reported that material removal rate reduces with the rise of gap width [29]. The larger kerf widths reduces heat flux when other parameters are constant. The increase of plasma diameter may also decrease the heat flux [30]. Pulsed arc releases in the "gap" between tool electrode and workpiece which occupied with a 
dielectric fluid. The insulating effect of the liquid prevents the electrolysis of the electrodes during an EDM. A smaller gap $(10-100 \mu \mathrm{m})$ is necessary for precise machining as the shape of electrode is copied with an offset which is equal to the size of the gap. However a certain gap width is needed to avoid short circuiting depending on the type of electrode and electrolyte [31].

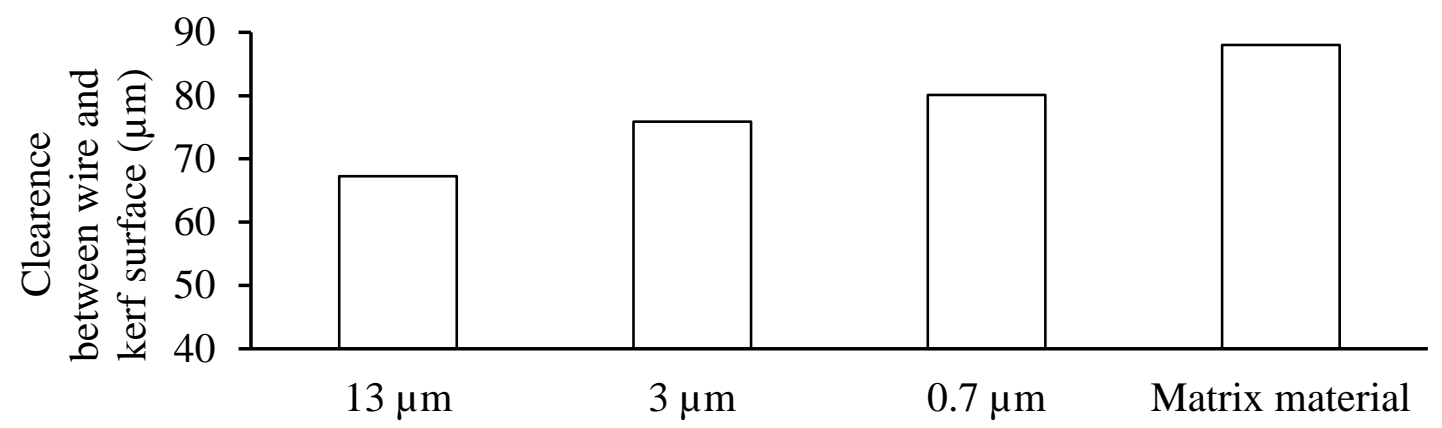

Fig. 11 Effect of particle size on the clearance between the electrode and kerf surface

In case when the particle size is larger $(13 \mu \mathrm{m})$ the inter-electrode gap/over cut/clearance is $67 \mu \mathrm{m}$. This means that the non-conductive and high melting point reinforced particles can be protruded partially into the matrix material and the other part can be over hanged in the over cut zone. Thus, the particles protect the matrix material from melting by creating a shield and reduce the speed of the wire electrode. A slow material removal rate during EDM process means the workpiece material gets more time to melt and provides a more consistent smoother surface. The Fig. 12 presents the effect of particle size on the EDM of MMCs. Fig. 12(a) shows the typical MMC and wire electrode at a distance where no electric spark takes place at the start of the EDM. The electric spark starts to take place when the wire electrode moves close enough to the workpiece. At this stage the matrix materials starts to melt and vaporize. When the size of the reinforced particles is bigger, the typical machining process will be similar to the Fig 12 (b). In this case the matrix material around the particles on the machined surface starts to disappear. However, the matrix material on the other side of the particles is shaded by particles from heat and takes time to melt which slows the material removal rate. At this stage the wire electrode keeps moving slowly toward the workpiece and results in reduced electrode gap and higher temperature. This causes higher wire electrode wear and smoother surface. The Fig 12 (c) shows the case when the reinforced particles are smaller the almost all the matrix melts and vaporize the particles may be attached to the workpiece material by a tiny link of matrix material. These links may be washed away with the flash of the electrolyte. The particles may provide minor resistance against the melting of $\mathrm{MMC}$ at this situation. With the further decrease of particle size, the resistance of melting becomes comparable to that of matrix material. 
The dominance of tiny craters related with the indiscriminate electric discharges cause rougher surface when machining the matrix material and MMCs reinforced with smaller particle (Fig. 12(c)).
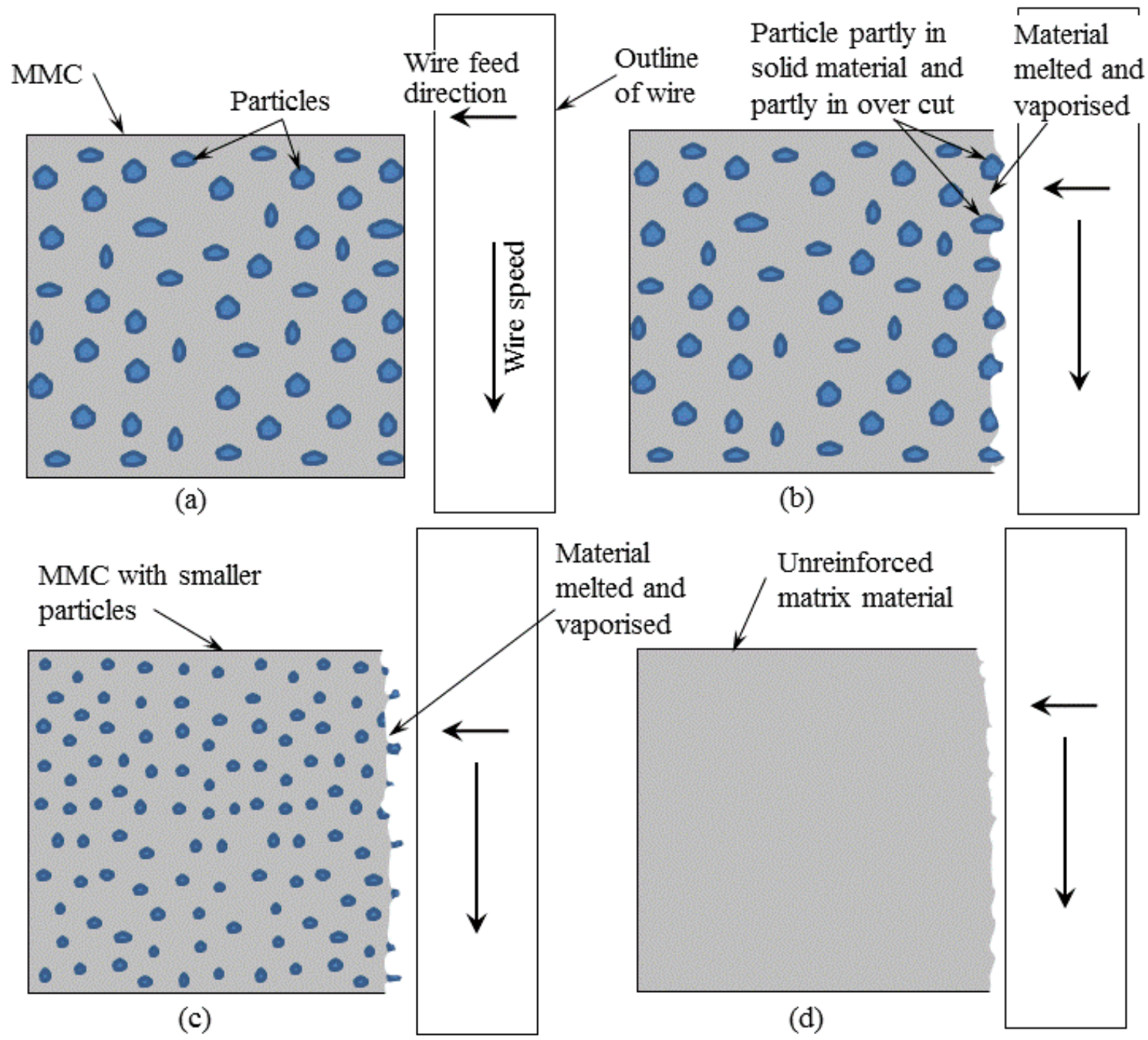

Fig. 12 Effect of particle size on EDM process of MMCs and matrix material

The previous study [22] indicated the presence of wire electrode materials $(\mathrm{Cu}$ and $\mathrm{Zn})$ in the machined surface only for MMCs as the slow material removal rate during EDM process allows the workpiece material to be in touch with intense temperature longer. Thus the transfer of material becomes easier for MMCs.

A typical surface generation process is already presented in Fig. 12. The surface generated by WEDM is made of many infinitesimal craters related to the arbitrary spark discharge between the electrodes. Thus, the surface finish is largely governed by the size of these craters. It was stated earlier that the SiC-particles don't melt in this process [32]. The matrix material melts and vaporises. There is a trend of the melted material to flow downward due to gravity. In addition, the wire 
electrode moves in two directions, i.e. the feed direction which is toward the workpice and the speed direction which is downward as shown in Fig. 12. The melting of the material occurs due to electric spark in point to point where many points take part at the same time. The spattering of the metals takes place in the inter-electrode gap which coats the wire electrode as well machined surface partially. Thus splash and flow of metals are noted on the wire electrode (Fig. 9) and machined surfaces (Fig. 3). Part of the melted material is solidified and removed by electrolyte. The residual liquefied material resolidifies at a tremendously high rate due to the flushing by the dielectric. Thus a re-cast layer of matrix material is generated [33]. Thus the machined surfaces appearance and roughness parameters are not affected significantly due to different sizes of reinforcements

The width of the kerf is always bigger than the diameters of the wire as the clearance requirements of EDM process and melting of the workpiece takes place around the wire during EDM [26]. The highest amount and bigger waves were noted in the slit/kerf profile of matrix material (Fig. 6). On the other hand, the waves were smallest and very few for the MMCs reinforced with bigest particles $(13 \mu \mathrm{m})$. It seems that speed/material removal rate is playing a role in this case. At slower material removal rate the the electrode wire gets more time to uniformly remove materials along the feed direction which produces smoother slit/kerf profile for MMC with reinforcements of bigger size. The dielectric-fluid atoms are affected by the stress between the negative electrode polarity and the positive workpiece polarity when a voltage is applied to the electrode and workpiece. This does not change the dielectric fluid until the electrode-to-workpiece voltage becomes equal to the dielectricstrength of the fluid. When these are equal, ionization occurs and electricity flows through the ionized column of dielectric fluid between the electrode and workpiece. The flow of electricity heats up the fluid and converts into a gas which is known as plasma which has equal number of free electrons positive ions. The electrons readily pass through the plasma in the form of a spark. At this stage, the negative electrons are enticed to the positively charged workpicce and the positive ions are appealed to the negatively charged electrode. Generally, ionization occurs for each spark and deionization occurs after the electricity is turned OFF [34]. Thus the coating of the workpiece material on the wire electrode is likely.

The fresh wire electrode at the top of the slit/kerf produces sparks with maximum energy which causes maximum melting and material removal from the surface. The electrode wire becomes contaminated (Figs. 8 and 9) with further machining. This may have reduced the energy of spark and gives better surface at the bottom of the slit/kerf for matrix material. When there are reinforcements in the matrix material at the entry of the machining, it protects the melting of the matrix material and reduces the damage. In case of MMCs, the damage and contamination of the electrode wire is severe 
which causes very inefficient machining at the bottom of the slit/kerf. This causes worse surface at the bottom of the slit/kerf. The bigger the size of the particles the higher the wire electrode is affected and the worse the bottom surface. On the other hand, the bigger the particle size the higher the protection of the matrix material and better the top surface of the slit/kerf.

It is already mention that the electrode wire has speed in feed direction as well as in downward direction as shown in Fig.12. At the start of EDM process a fresh portion of the electrode wire takes part in the machining. But after that the fresh wire enters into the slit/kerf from the top side and takes part in machining and then comes out from the bottom side of the slit/kerf. The wire enters the slit/kerf has bigger diameter and its diameter continuously decreases with the progress of machining due to electric discharge $[22,35]$. Then after machining, the wire comes out from the slit with a diameter much smaller than its original size. Thus, it is clear that along the height of the slit/kerf the wire diameter is different which produces different slit/kerf width. Thus, bigger width at the top side due to bigger wire diameter and smaller width at the bottom side due smaller wire diameter in bottom side [35]. In addition the, higher wear of the wire electrode causes bigger taper. In case of MMCs with $12 \mu \mathrm{m}$ the reduction of the wire diameter due to EDM process was maximum. This produced maximum tapered slot in this case. On the other hand, the smaller reduction of wire diameter in case of matrix material produce slot with minimum taper.

\section{Conclusion}

The conclusions from this study can be stated as given below.

(a) The presence of high melting point reinforcement protects the low melting point matrix material form melting and vaporizing which delays the material removal rate.

(b) The matrix at the back of the reinforcement particles melts at the end which causes longer heating, dislodgment of particles, diffusion of $\mathrm{Si}$ in the matrix materials and smoother material removal.

(c) The low melting point matrix material experiences splash of melted material, cavities and blisters very easily. Thus the machine surface is covered with matrix material and traces of wire electrode material.

(d) The wire surface also contains splash of melted material, cavities and blisters. Though the wire electrode is coated by matrix material, its diameter decreases with the EDM process due high temperature. The bigger reinforcement size induces higher wear electrode wire. 
(e) The wider slit/kerf was generated when the particles are smaller or there was no particle. The tapered slots were produced due to the wear of wire electrode during EDM of all the materials. The taper was reduced with the decrease of the reinforced particles.

\section{Reference}

1. Pramanik, A.; Arsecularatne, J; Zhang, L. Machining of particulate-reinforced metal matrix composites, in Machining. 2008, Springer. 127-166.

2. Pramanik, A.; Littlefair, G. Machining of Titanium Alloy (Ti-6Al-4V)-Theory to Application. Machining Science and Technology, 2015, 19(1),1-49.

3. Pramanik, A.; Zhang, L.; Arsecularatne, J. Micro-indentation of metal matrix compositesan FEM analysis. Key Eng Mater, 2007, 340, 341.

4. Luis, C.J.; Puertas, I.; Villa, G. Material removal rate and electrode wear study on the EDM of silicon carbide. Journal of Materials Processing Technology, 2005, 164, 889-896.

5. Ramasawmy, H.; Blunt, L. Effect of EDM process parameters on 3D surface topography. Journal of Materials Processing Technology, 2004, 148(2), 155-164.

6. Kumar, S. S.; Uthayakumar, M.; Kumaran, S. T.; Parameswaran, P. Electrical Discharge Machining of $\mathrm{Al}$ (6351)-SiC-B4C Hybrid Composite. Materials and Manufacturing Processes, 2014, 29(11-12), 1395-1400.

7. Pramanik, A.; Zhang, L.C.; Arsecularatne, J.A. Prediction of cutting forces in machining of metal matrix composites. International Journal of Machine Tools and Manufacture, 2006, 46(14), 1795-1803.

8. Singh, P.; Sidhu, S.S.; Payal, H. Fabrication and Machining of Metal Matrix Composites: A Review. Materials and Manufacturing Processes, 2015, DOI:10.1080/10426914.2015.1025976 (just-accepted).

9. Zhang, L.C.; Kiat, E.; Pramanik, A. A briefing on the manufacture of hip joint prostheses. Advanced Materials Research, 2009, 76, 212-216.

10. Muller, F.; Monaghan, J.; Verein Deut, I. Electro discharge machining of a particle reinforced metal matrix composite, in 12th International Symposium for Electromachining, 1998, 513522.

11. Singh, B.; Kumar, J.; Kumar, S. Influences of Process Parameters on MRR Improvement in Simple and Powder-Mixed EDM of AA6061/10\% SiC Composite. Materials and Manufacturing Processes, 2014, 30(3), 303-312. 
12. Sidhu, S.S.; Batish, A.; Kumar, S. Study of surface properties in particulate-reinforced metal matrix composites (MMCs) using powder-mixed electrical discharge machining (EDM). Materials and Manufacturing Processes, 2014, 29(1), 46-52.

13. Gatto, A.; Iuliano, L. Cutting mechanisms and surface features of WED machined metal matrix composites. Journal of Materials Processing Technology, 1997, 65(1-3), 209-214.

14. Rozenek, M.; Kozak, J.; Dabrowski, L.; Łubkowski, K. Electrical discharge machining characteristics of metal matrix composites. Journal of Materials Processing Technology, 2001, 109(3), 367-370.

15. Guo, Z. N.; Wang, X.; Huang, Z. G.; Yue, T. M. Experimental investigation into shaping particle-reinforced material by WEDM-HS. Journal of Materials Processing Technology, 2002, 129(1-3), 56-59.

16. Zhenlong, W.; Xuesong, G.; Guanxin, C.; Yukui, W. Surface Integrity Associated with SiC/Al Particulate Composite by Micro-Wire Electrical Discharge Machining. Materials and Manufacturing Processes, 2014, 29(5), 532-539.

17. Yan, B. H.; Tsai, H. C.; Huang, F. Y.; Lee, L. C. Examination of wire electrical discharge machining of $\mathrm{Al}(2) \mathrm{O}(3) \mathrm{p} / 6061 \mathrm{Al}$ composites. International Journal of Machine Tools \& Manufacture, 2005, 45(3), 251-259.

18. Patil, N.G.; Brahmankar, P. K. Some investigations into wire electro-discharge machining performance of $\mathrm{Al} / \mathrm{SiC} \mathrm{p}$ composites. International Journal of Machining and Machinability of Materials, 2006, 1(4), 412-431.

19. Manna, A.; Bhattacharyya, B. Taguchi and Gauss elimination method: A dual response approach for parametric optimization of CNC wire cut EDM of PRAISiCMMC. International Journal of Advanced Manufacturing Technology, 2006, 28(1-2), 67-75.

20. Saha, P.; Tarafdar, D.; Pal, S. K.; Saha, P.; Srivastava, A. K.; Das, K. Modeling of wire electro-discharge machining of $\mathrm{TiC} / \mathrm{Fe}$ in situ metal matrix composite using normalized RBFN with enhanced k-means clustering technique. The International Journal of Advanced Manufacturing Technology, 2009, 43(1-2), 107-116.

21. Liu, J.W.; Yue, T.M.; Guo, Z.N. Wire Electrochemical Discharge Machining of A12O3 Particle Reinforced Aluminum Alloy 6061. Materials and Manufacturing Processes, 2009, 24(4), 446-453.

22. Pramanik, A.; Basak, A.; Islam, M.N. Effect of reinforced particle size on wire EDM of MMCs. International Journal of Machining and Machinability of Materials, 2015, 17(2), 139-149. 
23. Sidhu, S.; Batish, A.; Kumar, S. Analysis of residual stresses in particulate reinforced aluminium matrix composite after EDM. Materials Science and Technology, 2015, 1743284715Y. 0000000033.

24. Basak, A.; Pramanik, A.; Islam, M. Failure Mechanisms of Nanoparticle Reinforced Metal Matrix Composite. Advanced Materials Research, 2013, 774, 548-551.

25. Pramanik, A.; Littlefair, G. Fabrication of nano-particle reinforced metal matrix composites. Advanced Materials Research, 2013, 651, 289-294.

26. Pramanik, A. Developments in the non-traditional machining of particle reinforced metal matrix composites. International Journal of Machine Tools and Manufacture, 2014, 86, 4461.

27. Pramanik, A. Electrical Discharge Machining of MMCs Reinforced with Very Small Particles. Materials and Manufacturing Processes, 2015, DOI: 10.1080/10426914.2015.1048360.

28. Hocheng, H.; Lei, W.T.; Hsu, H.S. Preliminary study of material removal in electricaldischarge machining of SiC/Al. Journal of Materials Processing Technology, 1997, 63(1-3), 813-818.

29. Tricarico, C.; Delpretti, R.; Dauw, D.F. Geometrical Simulation of the EDM Die-Sinking Process. CIRP Annals - Manufacturing Technology, 1988, 37(1), 191-196.

30. Kojima, A.; Natsu, W.; Kunieda, M. Spectroscopic measurement of arc plasma diameter in EDM. CIRP Annals - Manufacturing Technology, 2008, 57(1), 203-207.

31. Kunieda, M.; Lauwers, B.; Rajurkar, K. P.; Schumacher, B. M. Advancing edm through fundamental insight into the process. CIRP Annals - Manufacturing Technology, 2005, 54(2), 64-87.

32. Hung, N.P.; Yang, L.J.; Leong, K.W. Electrical discharge machining of cast metal matrix composites. Journal of Materials Processing Technology, 1994, 44(3-4), 229-236.

33. Ho, K.H.; Newman, S.T. State of the art electrical discharge machining (EDM). International Journal of Machine Tools \& Manufacture, 2003, 43(13), 1287-1300.

34. Jameson, E.C. Electrical discharge machining. 2001: SME.

35. Pramanik, A., Electrical discharge machining of 6061 aluminium alloy. Transactions of Nonferrous Metals Society of China, 2015, 25(9), Manuscript ID TNMSC-2014-0528.R1. 